\title{
The WHO EMF Project: Legitimating the Imaginary of Global Harmonization of EMF Safety Standards
}

\author{
DAVID MERCER \\ UNIVERSITY OF WOLLONGONG
}

\begin{abstract}
An important topic for studies of STS and globalization are the ways "global" institutions create and attempt to implement health guidelines and safety standards to address risks associated with new technologies. In the following discussion this topic is examined through a case study of the activities of the World Health Organization's Electric and Magnetic Field Project (WHO EMF Project). EMF exposures are associated with telecommunications and electrical infrastructure, most notably high voltage power-lines, radio and cell towers and the use of mobile telephones. The controversy over setting international safety standards and health guidelines has simmered for a number of decades. The mainstream "regulatory science" position has been that it is unlikely EMF's constitute a significant health risk and therefore minimal regulatory intervention or significant precautionary considerations are required. A small but persistent stream of scientific studies nevertheless have continued to raise significant health concerns and have led to calls for regulators to build stronger precautionary approaches into EMF standards and guidelines. The WHO EMF project was established in 1996 in an attempt to discourage this situation leading to different nation states adopting strong precautionary approaches and developing a diversity of national EMF safety standards and health guidelines. In the following discussion I will explore the history of the WHO EMF Project and the strategies it has used to pursue its goal of global harmonization of EMF science, safety standards and guidelines. Three important strategies used by the WHO EMF Project have involved: appeals to technological determinism, developing bespoke models for sound science, and setting the boundaries between science and policy to attempt to exclude their opponents from the policy making arena.
\end{abstract}

\section{Keywords}

World Health Organization; safety standards; risk; electro-magnetic fields; scientific controversy

' David Mercer, Email: dmercer@uow.edu.au

Copyright (C) 2016 (David Mercer). Licensed under the Creative Commons Attribution Non-commercial No Derivatives (by-nc-nd). Available at estsjournal.org. 


\section{Introduction}

This paper contributes to a growing body of STS studies that are preoccupied with providing a better understanding of global knowledge-making institutions. Such studies have been primarily concerned with understanding the circumstances in which these institutions emerge and become parts of regulatory regimes; the kinds of relationships they have had with nation states and local knowledge(s) and institutions; how they attempt to maintain legitimacy for their actions; and what sorts of political influences have they exerted (Jasanoff 2004; Jasanoff and Martelo 2004; Miller 2007; Winikoff and Bushey 2010; Daemmrich 2012).

Winikoff and Bushey (2010) have noted that one of the distinctive contributions STS studies have brought to understanding these issues has been an interest in exploring their epistemic dimensions. This has included describing the patterns involved in the way global knowledge-making institutions construct and put to use standardized forms of reasoning, such as those involved in discourses surrounding "risk analysis" and "sound science," and the ways they engage in "boundary work" to attempt to include or exclude the knowledge claims of neighboring institutions (Gieryn 1999).

Many of these STS studies have been carried out within the "coproductionist idiom" (Jasanoff 2004). Within this idiom politics and science are not treated as discrete entities, and so analytical focus is shifted toward documenting the way various knowledge making practices, institutional arrangements and political power come together (are co-produced) in mutually reinforcing hybrid forms (Winikoff and Bushey 2010).

As a case study of the dynamics involved in the emergence and maintenance of a global knowledge making institution, I will explore the history and ongoing activities of the World Health Organization's Electric and Magnetic Field Project (EMF Project) and its attempts to create and harmonize global health and safety guidelines addressing possible health risks of exposure to Electrical and Magnetic Fields (EMF). EMF exposures are commonly linked to electrical and telecommunications infrastructure and in recent times most notably mobile telephones (cellphones).

Whilst the EMF project has experienced some success in harmonizing international EMF exposure standards/guidelines, its tendency to minimize the significance of scientific uncertainties in shaping its assessment of EMF risk, and its ambivalent approach to incorporating precautionary measures into guidelines/standards, have been subject to persistent criticism from activists and dissenting scientists. In turn, a number of nation states have resisted complying with its recommendations (Pascual 2013).

The analysis that follows will explore the way the EMF Project has used three interlocking strategies to defend its efforts to harmonize EMF guidelines/standards and challenge the legitimacy of alternative national policy approaches and alternative scientific assessments of EMF health risks. These can be described as follows: 
(1) Using technological determinist rhetoric to trivialize local/national concerns;

(2) Developing bespoke models of science (method discourses) that dovetail with the EMF Project's regulatory agenda and institutional identity;

(3) Framing the boundaries between science and policy to exclude precautionary policies from appearing on the "map" of legitimate EMF science, whilst at the same time extending the boundaries between science and policy to expand the EMF Project's scientific authority into wider policy arenas.

I will close discussion by describing the cumulative effect of these strategies, which has been to promote the EMF Project as an "obligatory point of passage" for nation states dealing with the EMF controversy.

\section{Background Context: A Short History of the WHO EMF Project}

In the 1970s-80s many Western nations witnessed a spike in the growth of consumer electronic products, a spread of electrical and telecommunication infrastructure, and military applications involving EMF, such as new radar defense systems. In response, questions began to emerge in public settings about the lack of knowledge regarding possible health risks associated with EMF exposures linked to these new technologies. Anxieties were heightened by the publication of epidemiological studies suggesting possible associations between cancer and exposure to various EMFs. They were further amplified when they frequently became linked to planning disputes involving the sighting of new EMF emitting electrical and communication infrastructure and when it became widely known that EMF safety guidelines in Eastern European countries were far stricter than in the West.

In response to these concerns, the appropriateness of existing EMF exposure guidelines/standards became the focus of a number of relevant national and international regulatory and advisory reviews. One of the most important international organizations to become involved was the International Radiation Protection Agency (IRPA). IRPA set up working parties to investigate possible health problems arising in relation to EMFs. These efforts ultimately lead to the formation of the International Committee for Non-Ionizing Radiation Protection (ICNIRP) in 1992. In May 1996 ICNIRP's inaugural chairman Michael Repacholi established the World Health Organization EMF Project. Repacholi stepped aside as its chair in 2006 (passing the role on to Emilie van Deventer) but has exercised a continuing influence as Chairman Emeritus and lifetime non-voting member of ICNIRP (Pascual 2013). Repacholi provides a personal perspective on the establishment of the project:

\footnotetext{
${ }^{2}$ For a history of earlier years and debates about setting standards for Non- Ionizing Radiation see: Brodeur (1977), Schwan (1984), Steneck (1984), Smith and Best (1989) and Mercer (1994).
} 
I started the International EMF Project at the WHO because we were in the midst of a technological revolution and there was considerable concern about possible health effects from the EMF exposure they produced. The WHO was a very appropriate international umbrella organization that was highly respected by various national health authorities and had some 50 years experience in assessing the health risks from exposures to various chemicals, biological and physical agents. As I had been working with the WHO since 1976 and knew the system well I was asked by the WHO to start the EMF project and get the funding for it. (Repacholi 2007)

The EMF Project's goals have been ambitious and broad. They range from providing national governments and NGO's with EMF health risk assessments, information on risk perception, risk communication and risk management, to reviewing the scientific literature on biological effects of EMF exposure, identifying gaps in knowledge, and setting the agenda for EMF research. In outreach materials the EMF Project says that it pursues these goals in a transparent and consultative fashion, with the project being "open to any WHO member state government, i.e. departments of health, or representatives of national institutions concerned with radiation protection" (WHO 2015). The EMF Project's web site notes the success of its inclusive approach, noting that since its commencement over fifty national authorities have been involved (WHO 2015).

Critics of the EMF Project have suggested that it has fallen well short of achieving its goals. There have been numerous claims that the WHO has allowed commercial interests from the electrical and telecommunication industries (who have provided up to 50\% of the EMF Project's funding) to influence the direction of EMF research and policy formation, ahead of other stakeholders and non- ICNIRP scientists (Maisch 2006; Slesin 2005, 2006). Critics have also used ad hominem arguments to suggest that the mere fact that the EMF Project was a WHO project didn't mean that its activities should not be open to scrutiny. References were made to the controversy as to whether the WHO's pronouncement of a Swine Flu pandemic in 2009 had been premature and motivated in part by possible benefits flowing on to members of the relevant WHO committee that had links to pharmaceutical companies producing "Swine Flu" Vaccines (O'Dowd 2010; for a broader historic overview see Lakoff 2015). Critics also noted a report published in the Lancet in 2007, which suggested that WHO guidelines were often not evidencebased, failed to use the WHO's own criteria, and were over reliant on using advice and opinions of a small number of preferred elite experts (Oxman, Lavis and Fretheim 2007). The EMF Project's strong reliance on the deliberations of the relatively small ICNIRP committee appeared to some EMF activists to offer an exemplar of these sorts of problems (Pacual 2007).

Repacholi defended the EMF project against these criticisms by noting that it consulted widely and drew upon an expansive scientific database and went to significant lengths to guarantee the independence of its advice and ensure that researchers were free from interference (Repacholi 2007). Notably, in recent years the EMF project maintains that the possible conflicts of interest of its contributors need to be declared (WHO 2010).

At a deeper epistemic level, though, various critics have suggested that ICNIRP's origins in Ionizing Radiation protection (mainly concerned with Nuclear Radiation) have encouraged it 
to adopt a scientific approach to the EMF question in a way that is dominated by traditional BioPhysical ahead of more novel Bio-Medical approaches. Traditional Bio-Physics oriented approaches proceed as a matter of theoretical "first principles" that low level EMF's are highly unlikely to be a risk to public health because of the extremely low levels of energy involved in most possible exposures. These approaches are generally described as being "thermalist" or "energy" oriented. The thermal approach suggests that the only relevant EMF biological interactions that require regulation are those resulting from exposures-in the case of lower frequencies, those that involve enough energy to induce harmful electrical currents in living things and, in the case of higher frequencies, those stimulate heating of cells and tissues (Steneck 1984; Dalton 1991; Miller 2003). With the exception of some industrial, military and medical applications, most day-to-day exposures from EMF emitting technologies, such as cell phone towers, power-lines and mobile telephones, produce exposures considerably below those producing well understood thermal or energy effects (Park 2000; Anderson 2014).

This orientation has arguably also discouraged ICNIRP and the WHO from engaging in anything beyond a symbolic (perhaps even reluctant) incorporation of precautionary policies into EMF health guidelines/standards. The EMF Project's approach to precaution has been criticized as symbolic as safety margins are set far too high to suggest that they have been developed with any serious consideration of "athermal" scientific studies. This means they offer the appearance of addressing scientific uncertainties whilst substantially ignoring them (Slesin 2005). Interestingly some more outspoken "thermalist" oriented scientists have also critiqued, as symbolic, the ICNIRP/WHO safety margins in guidelines/standards, because they believe "the EMF science" suggests safety margins should be set much higher than current levels (Anderson 2014).

Ambivalence regarding precautionary policies has also been displayed by van Deventer and Repacholi who have regularly suggested that care should be taken in discussing precautionary policies because such discussion can amplify public awareness of scientific uncertainties that are then frequently inappropriately converted (in the public's imagination) into evidence for EMF risks (Foster and Huber 1995; Foster and Repacholi 2000; Park 2000; Burgess 2004; de Venter and Foster 2008; Repacholi 2015; WHO 2015).

Aside from the question of whether or not mentioning precaution has amplified public concerns with EMF risk, ICNIRP's reluctance to substantially incorporate precautionary considerations into its guidelines/standards has been an important factor that has contributed to a significant number of WHO EU member states' resistance to adopting them and setting down stricter EMF guidelines/standards (Pascual 2013). These concerns about appropriate "precaution" in EMF safety guidelines/standards have also appeared in various government reports, most notably the UK government's Stewart report (Stilgoe 2005).

Disquiet in EU States with ICNIRP's lack of precautionary considerations toward EMF has also spread to litigation. In a case in Italy in 2012 a mobile telephone carrier was forced to pay compensation to a plaintiff who alleged that EMF exposures relating to their mobile telephone use could be linked to their development of a brain tumor. In the judgment the WHO was 
singled out as not offering an impartial view on the possible links between EMF/RF from mobile telephone use and brain tumors (Moskowitz 2012).

Whilst these debates have provided persistent challenges to the EMF Project's legitimacy there is also a sense in which the EMF Project has also been able to exploit these uncertainties and disagreements and use them to help justify its continuing role. The need for regulators to obtain coherent overviews of the complex and contested scientific questions raised by EMF, which often span multiple scientific disciplines that are also friendly to their policy making needs, has provided an obvious demand for the mix of administrative, regulatory and scientific skills offered by ICNIRP and the WHO (Pool 1991). As will be discussed in more detail in the second part of the paper the EMF Project can offer regulators "a view from everywhere" and the promise of "disciplining diversity" (Selser 2009).

ICNIRP's influence has grown as it has become increasingly adept at capturing financial resources (more than 270 million dollars committed by 2007), developing informal and formal communication networks, and steadily (although not without challenges) integrating its scientific work with regulatory demands (Mercer 2009). These efforts can also be understood, to use Jasanoff's terminology, as a form of "co-production." The term co-production is used in this context to capture the sense that the EMF project is engaged in a process of systematically creating durable institutional arrangements and linked epistemic frameworks to attempt to sustain its activities (Jasanoff 2004; Winikoff and Bushey 2010).

Although initially envisaged to run for five, years the EMF Project is still operating twenty years later (Repacholi 2007; de Venter 2014). The EMF Project has been a success and has become a role model for other similar WHO projects. Again quoting Repacholi:

I initially managed just the EMF project. However the Project became so successful that the WHO asked me to manage the whole radiation program: including EMF, ultraviolet radiation and ionizing radiation. (Repacholi 2007)

Other more recent and specific factors have also assisted in keeping the EMF controversy alive during the EMF Project's tenure. This has included the inability of a comprehensive multinational epidemiological study of mobile telephones and brain tumor risk-the so called Interphone study (Cardis et al. 2010)--to dismiss the possibility of links between brain tumors and mobile telephone use; the classification in 2011 of RF radiation as a possible carcinogen by the International Agency for Research into Cancer; persistent scientific reviews dissenting from "mainstream" EMF science; and the ongoing development of new EMF/RF emitting technological systems. I will expand on these points in order.

The Interphone study was coordinated by the International Agency for Research into Cancer (IARC), an advisory member of the WHO. Published in 2010, Interphone brought together epidemiological studies of mobile telephone use and brain tumors from thirteen nations. Interphone concluded that there was a possible link between heavy mobile telephone use and brain tumors (primarily glioma) and possible protective effects against brain tumors with lower exposures (IARC 2010). Interphone was quite open in noting that it had encountered 
methodological challenges that might help to explain its unusual findings (Cardis et al. 2010). A number of commentators also noted ongoing disagreements between various scientists involved in the study, which had delayed its publication for a number of years. Given these circumstances it is perhaps not unsurprising that the Interphone study generated contradictory media headlines, crediting it both with dismissing mobile telephone-brain cancer risk and affirming it (Slesin 2010, 2011).

After a comprehensive review of the relevant scientific evidence, in 2011 the IARC classified RF radiation as a 2B possible carcinogen (IARC 2011; Lancet 2012), which added to this climate of uncertainty. It placed RF radiation in the same classification as lead and napthalene, but also more mundane things like pickled vegetables and coffee (the latter linked to urinary, bladder and large bowel cancer). In the wake of the IARC classification, calls for further EMF research and precautionary considerations were made both by activists and by some members of IARC itself (Armstrong 2012). Because of IARC's relationship with the WHO, IARC's classifications offered an interesting challenge to ICNIRP's "standard" setters. These connections meant that EMF activists could now attempt to undermine the WHO/ICNIRP guidelines and standard setting approaches by selectively quoting parts of documents produced by the IARC, which also contained the WHO logo and imprimatur (Davis 2016). Complimenting uncertainties within "mainstream" EMF science perspectives, the EMF project has also had to contend with "alternative" reviews of EMF science that have dissented from "thermalist" approaches. The most important examples have been the "Bio-initiative Reports" (Sage and Carpenter 2012). These reports collated contributions from various scientists who dissent from the EMF "thermal" mainstream scientific position and call for stricter approaches to EMF regulation. The reports have largely been ignored by ICNIRP for purposes of guideline/standard setting, and have been criticized by various government authorities and scientists with long informal associations with the EMF Project (ARPANSA 2013; Foster and Trottier 2012).

Another challenge to EMF Project has been yet another surge in the introduction of new $\mathrm{RF} / \mathrm{EMF}$ technologies. Whilst telecommunications and information technology have undergone continuous rapid changes for a number of decades, the recent expansion of cell tower networks, smart meter technology for monitoring and billing electricity usage and $\mathrm{Wi}-\mathrm{Fi}$ in classrooms and workplaces has been particularly publicly prominent (Hesse and Coley 2012). These technologies involve exposing the broader population to ubiquitous extremely low levels of involuntary EMF exposure and have, in addition to raising concerns about cancer risks, contributed to claims that some susceptible individuals may be suffering from a broad spectrum of lesser health complaints because they are electro-sensitive. Some of these concerns have prompted litigation (White 2015; Crozier 2013; Australian Administrative Affairs Tribunal 2013). Ironically, a factor in promoting awareness of the possibilities of electro-sensitivity came from within the ranks of the WHO itself. During her term as head of the WHO, Gro-Harlem Brundtland raised the ire of ICNIRP by publicizing her beliefs that her excessive mobile telephone use was causing her headaches and ill health, and that she had developed a form of electro-sensitivity. These matters were topics of discussion in Norwegian Parliament and generated a public rebuke from Repacholi (Slesin 2012). 
In short, the EMF Project has emerged and operates in a context where it has achieved the status of the premier global scientific/regulatory voice on the EMF question. But this hegemonic position is still a troubled one as various nation-states have resisted the wholesale adoption of its recommendations - particularly regarding the question of precautionary considerations. Though it claims to represent a transparent appraisal of the breadth of the relevant EMF science, it has been continuously challenged by activists and a dissenting scientific minority. These challenges also need to be set against the backdrop of uncertainties about new forms of EMF exposure patterns linked to the emergence of new EMF emitting technologies and technological systems.

In the next section of discussion I will move on to provide an analysis of the three key strategies used by the EMF Project to respond to these challenges and pursue the defense of its deeper, longer standing commitment to keep the EMF debate within its sphere of influence and reinforce its version of the dominant scientific/regulatory paradigm for understanding EMF risk.

\section{Three Strategies for Legitimating the Global Harmonization of EMF Safety Standards}

\section{The use of technological determinist rhetoric}

Techno-deterministic imagery appears most conspicuously in debates around the development of new technologies (Wyatt 2008). In their simplest forms, technological determinist styles of thought emphasize that human agency is limited in its capacity to initiate or fundamentally shape technologies and is at best reactive or adaptive (Mathewman 2011). In global regulatory contexts, such a "mind-set" often appears in terms of treating national and local differences in the uptake and resistance to technologies as impediments to what are assumed to be their universal / trans-national implications and demands. Within this technocratic frame, the possibility that technologies can take different paths, be regulated differently, and function in different ways in different contexts, are treated as aberrations. Following from this, local differences or resistance to new technologies requires sociological/political explanation and regulatory remedy (Winikoff and Bushey 2010).

In her comparative studies of international and national risk regulation, Sheila Jasanoff has noted that this universalizing, determinist way of thinking about the regulation of technology ignores the realities that different nation states can have different "civic epistemologies" that influence the way new technologies are regulated. Civic epistemologies are shaped by their respective national contexts: having different decision-making and legal traditions; different attitudes toward the responsibilities of institutions and experts; and different cultural perceptions of the risks or promises of the particular science and technology in question (Jasanoff 2005).

For Jasanoff, harmonization or globalization of innovation is not natural or inevitable but rather an outcome of political negotiations, settlements, and sometimes struggles. For global knowledge-making institutions (such as the EMF Project), using rhetoric that treats various technological trajectories as inevitable helps to obscure the fact that they are the type of actors who are playing an important role in initiating globalization and not simply facilitating an inevitable process (Miller 2007; Winikoff and Bushey 2010). 
There are a number of examples where subtle forms of technological determinist rhetoric in the EMF Project help to naturalize the need for the harmonization of standards and attempt to render the EMF Project as an apolitical actor. In the first example (below) the image that it is inevitable that EMF exposures will continue to increase as a result of new technology is promoted. This gives the EMF Project's mandate both urgency and the need for continuity:

Electromagnetic fields of all frequencies represent one of the most common and fastest growing environmental influences, about which anxiety and speculation are spreading. All populations are now exposed to varying degrees of EMF, and the levels will continue to increase as technology advances. (WHO 2015)

It is important to add that whilst "increased advances" in EMF emitting technologies probably lead to more ubiquitous low level EMF exposures, they don't necessarily lead to increased intensity of individual EMF exposures. For example, newer designs of mobile telephones may now produce lower exposure levels than older models because of various efficiency improvements that allow lower power outputs. Further, the spread of optic fiber cable broadband and Internet services may lead to lower needs for RF emitting towers and renewing electrical infrastructure can involve incorporating better wiring configurations and cabling location resulting in reducing public exposure to extra low frequency EMF's. Finally, things like the popularity of text messaging can lead to fewer voice calls, so radiation emitting telephone handsets are spending less time in close proximity to user's heads.

Other technological determinist arguments for harmonization take the forms of warning nation states of the possible negative consequences of the adoption of different standards from ICNIRP's. It is suggested that such standards will inconvenience manufacturers and also hold back national technological development:

Large disparities between national limits and international guidelines can foster confusion for regulators and policy makers, increase public anxiety and provide a challenge for manufacturers and operators of communication systems who need to tailor their products to each market (WHO 2006, 7). Will the more conservative limits be a barrier to the introduction of new technologies which may have significant benefits to health and international trade? (WHO 2006, 15)

Whilst arguments linking technological convergence, standardization and globalization are relatively common-and have some intuitive and empirical support--treating the possibility of more conservative limits, and resistance to one particular model of harmonization (ICNIRP's) as a barrier to innovation, relies on technological determinist simplifications. Contrary to the WHO's assertions, many studies of technological innovation have indicated that stricter environmental regulation can, in some contexts, be an economic stimulant and incentive to the development of new, more efficient technologies (Taylor, Rubin and Houndshell 2005).

It is also worth noting that the links between the EMF Project's version of global harmonization and technological determinism privilege a particular vision of globalization (one 
which may be common but not inevitable), where technological innovation spreads from the active core of designers to the passive periphery. For example, in stating that manufacturers of telecommunication systems will be challenged by having to tailor their products to each market, it is assumed that there are no opportunities for local input into design, manufacture and operation of such products. The history of the emergence of text-messaging capacities for mobile telephones, for example, reflects the importance of users in shaping technological innovation: manufacturers of mobile telephones initially didn't anticipate that "texting" would become a major component of mobile telephone communication (Trosby 2004; Mercer 2006).

\section{Developing bespoke models of science (method discourses)}

A common feature of public scientific controversies is the evolution of what could be described as "scientific method discourses," or, "bespoke models" of what should count as "sound" science in a specific context. By "bespoke" I am highlighting the sense in which models of science are quite literally "made to measure" in anticipation of their fit with various desired policy outcomes (Schuster and Yeo 1986; Mercer 2002; Scott 2005).

These tendencies appear most strongly in longer-standing scientific controversies where adversaries have the opportunity to refine their arguments in response to their opponents over time. In these contexts, merely stating a "factual" position, or appealing to individual or institutional authority, is unlikely to close a debate, and experts find themselves being asked to publicly explain their methodologies and reasoning (Porter 1995; Mercer 2002).

As noted earlier, the EMF Project has been regularly subject to critiques from activists that it fails to consider a large number of scientific studies relevant to the EMF question. Not surprisingly, then, its "method discourse" primarily plays an anticipatory and defensive role, engaging in detailed arguments for why various studies cannot be included for regulation. At the most general level, its "method discourse" notes that extrapolating results from studies that use exposures levels that differ from exposures in real world settings should be avoided; that weak epidemiological associations in the absence of well understood causal mechanisms should not be considered; and that, because the quality of peer review varies between journals, a study's successful pass through peer review is not enough in itself for it to be included in scientificallybased standard setting (Mercer 2009).

Overlapping with these more general considerations, additional specific criteria for assessing scientific research are also added. To paraphrase the EMF Project, these include:

(a) The importance of strength of association.

(b) The ability of a study to identify true risk without bias and confounding.

(c) The importance of a dose-response relationship between an EMF exposure and a health outcome. 
(d) The existence of laboratory evidence of whole animals-not just in-vitro cellular studies.

(e) Whether a study relies on plausible biological mechanisms to establish a link between EMF field exposure and the health outcome being considered.

(f) "Stand-alone" studies are of limited value, as "the existence of biological effects and health hazards can only be established when research results are replicated in independent laboratories or supported by related studies"' (WHO 2006, 15-21, 35-39).

In the political context surrounding the EMF question, these detailed criteria constitute a powerful resource to dampen and decelerate claims for stricter regulation or consideration of precautionary approaches. For example, the EMF Project's insistence on the need for ongoing "real world" measurement studies prior to considering causal mechanisms, and its demands that only strong epidemiological results underpinned by plausible biological mechanisms and independently replicated studies can be incorporated into guidelines/standard setting, results in the "thermalist" status quo favored by ICNIRP being privileged. This is the case because studies of EMF "thermal effects," which reinforce ICNIRP's EMF guidelines/standards, normally work with well understood mechanisms that can be replicated. This means even whilst "thermal" studies don't represent the wider cross-section of EMF science, they do satisfy the criteria to become the science of EMF regulation.

\section{Strategic framing of the boundaries between science and policy}

Dovetailing with its "method discourses" described above the EMF Project also engages in boundary work and cultural cartography (Gieryn 1999). Its boundary work is largely preoccupied with attempting to establish an imagined map of EMF science and policy that excludes its opponents whilst simultaneously expanding the sphere of its influence. Where its "method discourses" are rather abstract/anticipatory and defensive, the EMF Project's "boundary working" rhetoric is in a sense more pro-active.

A key theme that re-appears in various documents and public presentations associated with the EMF Project is that stricter alternatives to its guidelines/standards are irrational and unscientific. The EMF Project suggests that nation states mistakenly rely on their own inferior scientific databases and setting guidelines based on

deficiencies in communication among scientists between different regions as well as certain social differences. WHO 2006, 7)

\footnotetext{
${ }^{3}$ See Mercer (2009). For some similarities with the strategic use of images of "sound science" to inhibit stricter regulation in other health risk debates see Edmond and Mercer (2004) and Michaels and Monforton (2005).
} 
The EMF Project reinforces this conservative approach as to what types of science need to be considered for regulation, by emphasizing that the determinations of committees "with extensive experience and expertise" (like ICNIRP) and pre-existing reviews should be given the highest value for standard setting.

The EMF Project also challenges the strength of philosophies for setting guidelines/standards that consider possible biological effects of EMF as opposed to EMF health effects. This involves the boundary working rhetoric that distinguishes health effects and biological effects. For the purposes of the EMF Project's determination of exposure levels "mere" biological effects are partitioned out of the domain of scientifically-based standard setting. Harking back to its earlier technological determinist rhetoric the EMF Project also warns of the dire economic consequences of adopting such approaches:

Another way of determining exposure limits [an approach different to ICNIRP's] is to adopt a biological approach.... From the scientific database, a threshold exposure level is determined below which no biological effect is observed. This method alleviates the necessity of making a health risk assessment of the biological effects data and assumes an incomplete knowledge of the interaction mechanisms. This approach will result in an unduly conservative standard which could not only restrict technological advances but would be unacceptable in terms of loss of benefits accruing from technology: all for protection against questionable risks. This approach has been the basis for some Eastern European standards, leading to significantly lower exposure limits. (WHO 2006, 21-22)

The EMF Project also sets the boundaries between science and policy to include their sociological interpretations and policy preferences as part of their "science" based approach to EMF (Mercer 2009). In an address to a regional WHO workshop held in Melbourne in 2005, Emilie van Deventer (who took over the EMF Project's leadership from Repacholi) clearly articulates her belief that precautionary approaches different from those of the EMF Project are based on cultural, social and legal considerations:

[G]overnmental and industry authorities have responded by implementing a wide variety of different mandatory and voluntary precautionary approaches, based on cultural, social and legal considerations. (van Deventer 2005)

Van Deventer continues by asserting the EMF Project's authority by suggesting that alternative precautionary approaches undermine "the science," and are arbitrary and produce no health benefit:

WHO specifically recommends not to reduce limit values in international standards to some arbitrary level in the name of "precaution" since this undermines the science base on which the limits were based and can introduce an additional cost of compliance for no known health benefit. (van Deventer 2005) 
Van Deventer also extends the EMF Project's authority by challenging the legitimacy of its precautionary opponents on sociological grounds:

Also from a sociological standpoint, there is increasing evidence that making arbitrary reductions in exposure limits leads to increasing public concern rather than reducing it. (van Deventer 2005)

Overall, then, the EMF Project's boundary work rhetoric revolves around creating a number of dichotomies that set the EMF Project apart from its alternatives. These include the notion that the precautionary approaches favored by some nation states rely on deficiencies in communication; socio-cultural and legal differences; inferior national scientific databases; a confusion of biological effects with health effects; setting arbitrary exposure limits; and unnecessarily amplifying public concern. By (implied) comparison, the EMF project is an experienced communicator; it works with well-established international standards and agreements; it relies on well-established scientific international databases; it bases scientificallybased exposure limits on real health effects; and it is more sociologically informed in its dealings with the public.

This expansion of EMF Project's authority in dealing with the sociology of public concerns, is taken further when it offers to take on a pedagogical role in relation to the EMF issue. It does this by offering on its web site a map of the "EMF regulatory" world which can be "clicked on" to compare and contrast EMF standards/guidelines and identify which nation states have, or have not, achieved harmonization. The EMF Project's web site also provides links to paradigmatic exemplars of model regulation and templates, which regulators can use to construct their own WHO compliant standards and guidelines (WHO 2015).

\section{Concluding Comments}

The strategies used by the WHO EMF Project to attempt to control and shape the EMF debate reflects a confident "socio-technical imaginary" of a global EMF regulatory future. Sheila Jasanoff, and others, have explored the concept of socio- technical imaginaries in order to capture the ways in which various claims and approaches to technological possibilities are shaped by future holistic visions, which can embody implicit models of social relationships, roles and identities (Jasanoff and Kim 2015). The EMF Project's socio-technical imaginary is promoted by its rhetorical strategies that encourage a vision exhorting the "inevitable" benefits of harmonization and globalization of standards, the inevitable paths of technological innovation, and the EMF Project's "natural" role to assist in these processes. Within this imaginary, its public statements and guidelines are to be taken merely as attempts to allay confusion and guide rational policy making in relation to develop important new technologies.

The EMF Project's ongoing efforts are also amenable to a more historically and sociologically nuanced account that acknowledges the conflicted political and epistemic environment within which it has operated-- an environment where science and safety 
guidelines / standards haven't simply rationally spoken for "themselves" but have had their own contested histories. As has been shown above, the EMF Project has encountered resistance to harmonization of standards, particularly in parts of the EU and Eastern Europe, and faced a steady stream of criticism from activists for being unduly sympathetic to industry, overly reliant on ICNIRP, unresponsive to calls for more consideration of "non-thermalist" scientific perspectives, and resistant to considering precautionary approaches to risk management. The various strategies used by the EMF Project-such as the use of technological determinist rhetoric, developing bespoke models of science, and strategic framing and boundary ordering of science and policy—can all be seen as ways in which it has attempted to provide a "view from everywhere" in order to shore up its dominant role as the key global entity shaping EMF policy (Selser 2009).

Two deeper patterns have underlain these strategies. First, there has been a pattern of rhetorical defensiveness. This appeared in the repeated points at which the EMF Project anticipates and "closes down" alternative perspectives and critique by associating alternative EMF standards with a variety of negative processes and outcomes. That is, alternative standards inhibit technological progress; are based on irrational scientific miscommunication inappropriate databases and models for what counts as sound science; and are largely driven by irrational local/ nationally driven concerns. An effect of this defensiveness, in practical terms, is to attempt to relegate non-ICNIRP scientific and regulatory perspectives to inhabiting an alternative, inferior regulatory world that doesn't require serious consideration.

The second, deeper pattern underlying the EMF Project's strategies was of a more positive character. This involved the rhetorical construction of a "positive" EMF Project world, where the EMF Project became an obligatory point of passage for any one embarking on a journey into EMF regulation (Latour 1987). The EMF project imposes "its" "brand," and nuance on all the multiple layers of knowledge required to regulate EMF. A regulator, once they enter "the EMF Project/ ICNIRP world," can rely on research that the EMF Project has coordinated and funded, databases of scientific studies created using EMF Project endorsed criteria, standards and guidelines following ICNIRP endorsed "guidelines for establishing guidelines," Further, they can draw from model legislation.

This study of the EMF Project as a typical global knowledge making institution highlights the value of STS studies in recognizing the important ways in which such institutions engage in processes of hybrid political/epistemic co-production. The EMF project has not only engaged in constructing EMF scientific knowledge, an approach to EMF regulation and an institutional infrastructure to support these aims, but by combining these elements, has also built a powerful "hybrid" political/ epistemic WHO EMF Project world.

\section{References}

Administrative Appeals Tribunal of Australia. 2013. "McDonald and Comcare." AATA 105(28" February 2013).

Andersen, V. 2014. "1g vs 10g SAR average mass (and other related stuff)." Paper presented to ICNIRP Workshop: Radiofrequency Field Health Effects and Standards. Wollongong, 
$\begin{array}{llllll}\text { November } & 11 & 2014 . & \text { Accessed } & \text { October } & 19,\end{array}$ www.icnirp.org/cms/upload/presentations/rf/RFwshop_Anderson.pdf

ARPANSA. 2013. Review of Radiofrequency Health Effects Research-Scientific Literature 2000-2012. Report by the ARPANSA Radiofrequency Expert Panel. Australian Radiation Protection and Nuclear Safety Agency. Accessed May 10, 2015. www.arpansa.gov.au/pubs/technicalreports/tr164.pdf

Armstrong, B. 2012. "Do Mobiles Give You Brain Cancer? The Verdicts Still on Hold." The Conversation. 10 May 2012. https://theconversation.com/do-mobiles-give-you-braincancer-the-verdicts-still-on-hold-6939

Brodeur, P. 1977. The Zapping of America. New York, Norton.

Burgess, A. 2004. Cellular Phones: Public Fears and a Culture of Precaution. Cambridge: Cambridge University Press.

Cardis, E. (The Interphone Study Group). 2010. "Brain Tumour Risk in Relation to Mobile Telephone Use: Results of the interphone international case control study." International Journal of Epidemiology 39(3): 675-694.

Crozier, R. 2013. "Wi-fi allergies' issue flares up in Australia," itnews. Accessed 10, May, 2016. http:/ / www.itnews.com.au/news / wi-fi-allergies-issue-flares-up-in-australia-356354

Daemrich, A. 2012. "Epistemic Contests and the Legitimacy of the World Trade Organization: The Brazil-USA Cotton Dispute and the Incremental Balancing of Interests." Trade Law and Development (iv)1:200-240.Accessed 10" May 2016. http: / / tradelawdevelopment.com/index.php/tld/article/viewFile / 4\%281\%29\%20TL\%26 $\mathrm{D} \% 20200 \% 20 \% 282012 \% 29 / 127$

Dalton, L. 1991. Radiation Exposures. Australia: Scribe Publications.

Davis, D. 2016. "WHO/IARC position on wireless and health." Environmental Health Trust. Accessed 10 May, 2016, http://www.Ehtrust.org/science/whoiarc-position-on-wirelessand-health

Edmond, G. and D. Mercer. 2004. "Daubert and the Exclusionary Ethos: The Convergence of corporate and judicial attitudes towards the admissibility of expert evidence in tort litigation." Law and Policy 26(2):231-258.

Foster, K. and L. Trottier. 2013. "Picking Cherries in Science: The Bioinitiative Report." Science Based Medicine: Exploring Issues and Controversies in Science and Medicine. February 15, 2013. Accessed October 19, 2015, http:/ / www.sciencebasedmedicine.org

Foster, K. and P. Huber, (Eds.) 1994. Phantom Risk. Cambridge, MA: MIT Press.

Foster, K. and M. Repacholi and P. Veccia. 2000. "Policy Forum: Risk Management." Science (288): 979-981.

Gieryn, T. 1998. Cultural Boundaries of Science: Credibility on the Line. Chicago, IL: University of Chicago Press.

Hess, D. J. and J. S. Coley. 2014. “Wireless Smart Meters and Public acceptance: The Environment Limited Choices and Precautionary Policies." Public Understanding of Science. 23(6): 688-702.

International Agency for Research on Cancer (IARC). 2010. "Interphone Study Reports on Mobile Phone Use and Brian Cancer Risk." IARC Press Release No 200, 17" May 2010.

International Agency for Research on Cancer (IARC). 2011. "IARC Classifies Radiofrequency Electromagnetic Fields as Possible Carcinogenic Risk to Humans." IARC Press Release No 208, 31" May, 2011.

International Agency for Research on Cancer (IARC). 2016. IARC "IARC Monographs on the Evaluation of Carcinogenic Risks to Humans."

Jasanoff, S., (Ed.) 2004. States of Knowledge: The Co-production of Science and Social Order. Routledge: New York.

Jasanoff, S. 2005. Designs on Nature. Princeton, NJ: Princeton University Press. 
Jasanoff, S., and M. Martello (Eds.) 2004. Earthly Politics: Local and Global in Environmental Governance. Cambridge, MA: MIT Press.

Jasanoff, S., and S-H. Kim (Eds.) 2015. Dreamscapes of Modernity: Sociotechnical Imaginaries and the Fabrication of Power. Chicago: The University of Chicago Press.

The Lancet Oncology News. 2011. Carcinogencity of Radiofrequency Electromagnetic Fields (12) July 2011: 624 .

Lakoff, A. 2015. "Global Health Security and the Pathogenic Imaginary." In Dreamscapes of Modernity: Sociotechnical Imaginaries and the Fabrication of Power, edited by S. Jasanoff and SH. Kim, 300-320. Chicago: University of Chicago Press.

Latour, B. 1987. Science in Action: How to Follow Scientists and Engineers through Society. Cambridge, MA: Harvard University Press.

Maisch, D. 2006. "Conflict of interest and bias in health advisory committees: A case study of the WHO's EMF Task Group." JACNEM 21 (1): 15-17.

Mathewman, S. 2011. Technology and Social Theory. London: Palgrave.

Mercer, D. 1994. The NIEMR/EMF Controversy: The Social Construction of Scientific Knowledge and Science Policy in the "Gibbs" Powerline Inquiry 1990/91. PhD Thesis University of Wollongong, Australia.

Mercer. D. 2002. Scientific Method Discourses in the Construction of EMF Science" Social Studies of Science: 32:205-233.

Mercer. D. 2006. The Telephone: The Life Story of a Technology. Greenwood Technographies. Westport, Connecticut: Greenwood Press.

Mercer. D. 2009. “Defining Health, Policy and Science: Legitimating Vertically Integrated Expertise in the WHO EMF Project." In Yearbook 2008 of the Institute for Advanced Studies on Science Technology and Society, edited by A. Bamme, G. Getzinger and B. Wesier. 259-276. Munchen, Wein: Profil.

Michaels. D. and C. Monforton. 2005. “Manufacturing Uncertainty: Contested Science and the Protection of the Public's Health and Environment." American Journal of Public Health 95 (S1): 39-49.

Miller, C. 2005. "Novelty and Heresy in the Debate on the Non-thermal Effects of Electromagnetic Fields" in Rhetoric and Incommensurability, edited by Harris. R.A. West, 464-505. Layafayette, IN: Parlor Press.

Miller, C. A. 2007. "Democratization: International Knowledge Institutions, and Global Governance." Governance and International Journal of Policy Administration and Institutions. 20(2):325-357.

Moskowitz, J. 2012. "Italian Supreme Court Rules Cell Phones Can Cause Cancer" Accessed Oct 19, 2015, www.prlog.org/12004383-italian-supreme-court-rules-cell-phones-can-causecancer.html

O'Dowd, A. 2010. "Council of Europe Condemns 'Unjustified Scare' Over Swine Flu." British Medical Journal: 340:c303j.

Oxman, A. D., N. J. Lavis, and A. Fretheim. 2007. "Use of Evidence in WHO Recommendations." Lancet (369) 1883-1889.

Park, R. 2000. Voodoo Science. Oxford: Oxford University Press.

Pascual, G. D. 2013. "Not Entirely Reliable: Private Scientific Organisations and Risk Regulation The Case of Electromagnetic Fields." EJRR (1): 29-41

Pool, R. 1991. “Electromagnetic Fields: Little Accord on Priorities.” Nature (354) 260: 28/11.

Porter, Theodore. 1995. Trust in Numbers: The pursuit of objectivity in science and public life. Princeton, NJ. Princeton: University Press.

Repacholi, M. and, E. Cardis. 1997. “Criteria for EMF Health Risk Assessment." Radiation Protection Dosimetry. 72: 305-312. 
Repacholi, M. 1998. "Low-level Exposure to Radiofrequency Electromagnetic Fields: Health Effects and Research Needs." Bioelectromagnetics (19): 1-19.

Repacholi, M. 1999. “WHO's International EMF Project." Radiation Protection Dosimetry (83): 1-4.

Repacholi, M. 2007. "Gateway Interview with Michael Repacholi." RF Gateway Project New Brief, July 2007. Resource Strategies Inc. Madison, Wisconsin: USA. Accessed 19 October 2015, www.ext-up.org/pdf/GatewayInterview2MichaleRepacholiWhoEMFChief20070726.pdf

Repacholi, M. 2015. "Panel Discussion." Radio and Wireless 2015. RMIT University, Melbourne, Australia 8/10/2015. Accessed 10 May 2016, http://www.rmit.edu.au/events/allevents / conferences / 2015/ december/ science-and-wireless-2015/

Sage, C. and D.O. Carpenter, (Eds.). Bio-Initiative: "A Rationale for Biologically-based Public Exposure Standard for Electromagnetic Fields." Accessed May 25, 2016, http:/ / www.bioinitiative.org/

Schuster, J. and R. Yeo. 1986. The Politics and Rhetoric of Scientific Method. The Netherlands, Dordrecht: Reidel.

Schwan, H.P. 1985. "Historical Review, State of the Art, Open Problems" in Interactions Between Electromagnetic Fields and Cells: Proceedings of NATO Advanced Workshop, edited by A. Chiabrera, C. Nicolini, and H.P Schwan, 1-19. New York: Plenum Press.

Scott, D. 2005. "Nature/ Culture clash: The Transnational Trade in GMO's." Paper 254. Osgoode Hall Law School of York University Accessed 12 March 2016, http: / / digitalcommons.osgoode.york.ca/all_papers/ 254

Slesin, L. 2005. "WHO and Electrical Utilities: A Partnership on EMF's. Commentary from the Field." Microwave News, 1 October, Accessed 19 Oct 2015. http:/ / www.microwavenews.com/ fromthefield.html\#partners.

Slesin, L. 2006. "Commentary." Microwave News, 13 November. Accessed 19 Oct 2015.http:/ / www.microwavenews.com/ fromthefield.html\# partners

Slesin, L. 2010. "Interphone Resources." Microwave News May 17". Accessed 10th May 2016. http:/ / microwavenews.com/Interphone.Resources.html

Slesin, L.2011. "IARC: Cell Phone Radiation is a possible human Carcinogen. Small Group will file Minority Opinion." June 3, 2011 MicrowaveNews. Accessed 10, May, 2016, www.microwavenews.com/news-center/iarc-cell-phone-radiation-possible-humancarcinogen

Slesin, L. 2012. "Repacholi challenges Gro Brundtland EHS." Microwave News 29 May 2012, Accessed 19 Oct 2015, http:/ / www.microwavenews.com

Selser, P. 2009. "The View from Everywhere: Disciplining Diversity in post-World War Two International Social Science." Journal of the History of Behavioral Sciences, 45(4): 309-329.

Smith, C. and S. Best. Electromagnetic Man. Great Britain: Bath Press.

Steneck, N. 1984. The Microwave Debate. Cambridge, MA: The MIT Press.

Stilgoe, J. 2005. "Controlling Mobile Phone Health Risks in the UK: A Fragile Discourse of Compliance." Science and Public Policy. 32(1): 55-64.

Taylor, M, D. Hounshell and E. Rubin, "Regulation as the Mother of Innovation: The Case of S02 Control." Law and Policy. 27(2):327-348.

Trosby, F. 2004. "SMS, “The Strange Duckling of GSM." Telektronikk. March: 187-194.

van Deventer, E. and K. Foster. 2008. "Risk Communication for Electromagnetic Fields: A World Health Organisation Perspective." In The Role of Evidence in Risk Characterisation: Making Sense of Conflicting Data, edited by P. Weiderman and H. Schutz, 13-23. London: Wiley.

van Deventer, E. 2005. "Harmonizing Standards and Precaution." WHO Regional Workshop on Radiofrequency Fields: Health Effects and Policy Options for Protection. Thursday and Friday, 18 November 2005. Swinburne University of Technology, Melbourne, Australia.

van Deventer, E. 2014. The International EMF Project: Update on Radiofrequency Fields Environmental Health Criteria. Paper presented to ICNIRP Workshop: Radiofrequency Field Health Effects and 
Standards, Wollongong, November 11 2014.Accessed 21* Oct 2015, www.icnirp.org/cms/upload/presentations/rf/RFWshop_VanDeventer.pdf

Winikoff. D. and D. Bushey. 2010. "Science and Power in global food regulation: the rise of Codex Alimentarius." Science Technology and Human Values 35: 356-381.

World Health Organization EMF Project 2010. Research Agenda for Radiofrequency fields. Accessed 21Oct 2015, www.who.int/peh-emf/project/en

World Health Organization 2014. Establishing a Dialogue on Risks from Electromagnetic Fields. Geneva, Switzerland. Accessed 21/10/2015, www.who.int/peh-emf/publications/en/EMF_Risk_ALL.pdf.

World Health Organization. 2006. Framework for Developing HealthBased EMF Standards. Geneva, Switzerland. Accessed 21 Oct 2015.

www.who.int/peh-emf/standards/EMF_standards_framework[1].pdf

World Health Organization. 2015. "What is the EMF project?" Accessed 21 Oct, 2015, www.who.int/peh$\mathrm{emf} /$ project/en

White, M. 2015. "Brain on Fire." The Sydney Morning Herald Good Weekend September 15: 13-15.

Wyatt, S. 2008. "Technological Determinism is Dead; Long Live Technological Determinism." In Handbook of Science and Technology Studies, 3" edition, edited by E. J. Hackett, O. Amsterdamsk, M. Lynch, and J. Wajcman, 165-180. Cambridge, MA: MIT Press. 